INVESTIGACIONES

Narrativas audiovisuales e infancia contemporánea. Una lectura desde tres textos mediáticos

Grupo de investigación Infancia y Sociedad, Universidad Pedagógica Nacional

Infancia y ciudad. Una mirada desde las narrativas populares urbanas en Bogotá

Absalón Jiménez Becerra

¿De qué infancias hablan los educadores del nivel inicial?

Rosa Julia Guzmán Rodríguez

- Concepciones de infancia en el Programa de Educación Preescolar

Grupo de investigación Infancia y Educación, Universidad Pedagógica Nacional 


\section{Resumen}

La infancia ha cobrado en las últimas décadas una alta relevancia porque, según algunos autores, está desapareciendo; no obstante, lo que se evidencia es que se está transformando y que las narrativas audiovisuales son hoy, entre otros factores, un fenómeno de gran incidencia en dicha transformación, aportando representaciones desde donde los niños y adultos resignifican, desplazan e instalan configuraciones identitarias, en confluencia con las lógicas del mercado.

En este artículo se presenta una reflexión acerca del contexto de la época contemporánea al ocuparse de las narrativas audiovisuales que se generan sobre la infancia, indagando en tres textos mediáticos las imágenes que al respecto han circulado, y que constituyen insumos de producción de sentido, desde el cual la niñez define contornos particulares y se presenta como otra a los ojos sorprendidos de los adultos.

\section{Palabras clave:}

Subjetividades infantiles, mass media, narrativas audiovisuales, consumismo, individualidad, juvenilización, contexto de época.

\section{Abstract}

According to some authors, the childhood has gained high relevancy in the last decades due to the fact that it is disappearing; however, what is evident is that childhood idea is changing and audiovisual narrations are, at present, one phenomenon with a great incidence, among other factors, in such a transformation, giving representations from where both children and adults do re-mean, displace and establish configurations of identity according to the dialectics and rules of the market.

This analysis intends to be a reflection about the context of this contemporaneous age by dealing with the audiovisual narrations that are being made about childhood and inquiring throughout three mediated texts into the pertinent images showed so far which constitute the raw material for generating feelings and sense from which the children may define their particular environs and from which the childhood introduces itself like other different idea to the surprised adult's eyes.

\section{Keywords:}

Children's subjectivity, mass media, audiovisual narrative, consumerism, individuality, youthful, time context. 


\title{
Narrativas audiovisuales e infancia contemporánea. Una lectura desde tres textos mediáticos ${ }^{1}$
}

\author{
Ingrid Delgadillo Cely \\ Esperanza Bonilla Pardo \\ Luz Magnolia Pérez Salazar \\ Betty Sandoval Guzmán²
}

La sociedad contemporánea focaliza su actividad narrativa en el ámbito de los medios audiovisuales:

Las narrativas audiovisuales participan tanto de la construcción de la realidad socialmente compartida como de la interpretación del mundo que nos rodea. El estudio de las narrativas audiovisuales permite, por un lado, considerar la especificidad de estas formas de relato en relación con otras modalidades narrativas (...). Por otro lado, la investigación sobre las narrativas audiovisuales se conecta necesariamente con el análisis de los imaginarios sociales, la construcción de memorias sociales y diferentes formas de identidades colectivas e individuales (VI Bienal Iberoamericana de Comunicación, párrafo 1).

En este marco, los debates sobre las transformaciones contemporáneas sitúan en un punto nodal la fuerza de los medios de comunicación y las tecnologías informacionales en la generalización de ciertos modos de vida y en la complejización

\footnotetext{
1 Texto recibido el 8 de agosto, evaluado el 13 de septiembre y el 22 de octubre, y arbitrado el 31 de octubre de 2007.

2 Profesoras del grupo de investigación Infancia y Sociedad, del Proyecto Curricular de Educación Infantil de la Universidad Pedagógica Nacional. Ingrid Delgadillo Cely, es Magíster en Estudios de Género de la Universidad Nacional de Colombia y actualmente se encuentra vinculada al programa de Pedagogía Infantil de la Universidad Distrital Francisco José de Caldas, ingriddelgadillo@gmail.com; Esperanza Bonilla Pardo, es Magíster en Educación de la Pontificia Universidad Javeriana, espebonillap@hotmail.com; Luz Magnolia Pérez Salazar, es Magíster en Desarrollo Educativo y Social de la Universidad Pedagógica Nacional, luzmagperez@gmail.com y Betty Sandoval Guzmán, es Magíster en Educación Comunitaria de la Universidad Pedagógica Nacional, betsagu@gmail.com
} 
de las relaciones entre los sujetos, la política y lo social. Las discusiones sobre la infancia no son ajenas a esta reflexión; por el contrario, los autores interesados en el tema no dudan en responsabilizar a los mass media y a las nuevas tecnologías de las actuales configuraciones subjetivas de los niños contemporáneos.

$\mathrm{Al}$ respecto, los aportes de los estudios culturales frente a la relación de los sujetos con lo audiovisual comportan distintas posibilidades de lectura. Por una parte, destacan la capacidad de los sujetos de filtrar o significar los contenidos mediáticos desde sus universos culturales y, más específicamente, desde sus prácticas cotidianas. Por otra parte, contribuyen a mostrar cómo los medios de comunicación no son los únicos responsables de los cambios actuales, sino un elemento más en la urdimbre de las complejidades sociales. Sin embargo, desde una perspectiva crítica, algunos autores avanzan en el reconocimiento de la fuerza simbólica y de la inevitable afectación de lo mediático en los modos de significación que los colectivos van constituyendo sobre el presente y lo posible.

Frente a esta última perspectiva, Sodré (1998) argumenta que los discursos televisivos instalados en el centro de los espacios habituales e inmersos en el fluir cotidiano del ámbito familiar posicionan identidades, intereses y transformaciones culturales. Este punto de vista dio lugar a que los miembros del grupo de investigación Infancia y Sociedad ${ }^{3}$ preguntaran por los modos de presentar a la infancia en los textos mediáticos que circulan específicamente para la población infantil y que son de amplia aceptación familiar; textos en los que hay unos estereotipos de niñez y se representan modelos posibles de imitación, contrastación, interés, rechazo o mezcla.

Para indagar sobre las imágenes de infancia que promueven las narrativas audiovisuales, en el presente artículo se abordan fundamentalmente dos temas: los mass media y las subjetividades infantiles contemporáneas, y las infancias en El rey león, Yu-Gi-Ob! y Rebelde, tres textos mediáticos de distinto orden, pero significativos para los niños de acuerdo con el momento en el cual se estaban emitiendo.

\section{Los mass media y las subjetividades infantiles}

La comunicación entra a cumplir un papel determinante en las transformaciones de fines del siglo XX y principios del XXI, ya que es a través de redes de comunicación, satélites, telemática y nuevas tecnologías como se hace posible el desarrollo de esta nueva fase. Las transformaciones generadas tienen la dimensión de una revolución, según la expresión de Tadeu da Silva (1998), aluden a la mercantilización del saber y a la primacía del consumo, que desecha lo pasado, es ávido de lo novedoso, sin consideración del contenido y la significación del mismo.

La noción de lo nuevo se resignifica al tomar como eje de definición la velocidad del cambio y la uniformidad. En la perspectiva de Lipovetsky (1994), la

\footnotetext{
${ }^{3}$ El Grupo de investigación Infancia y Sociedad de la Universidad Pedagógica Nacional adelantó una investigación al respecto durante la vigencia 2004-2006.
} 
información es también una mercancía que se vende buscando un público cada vez mayor, y en este sentido lo que presentan los medios de comunicación, comprometidos en una competencia comercial permanente, es una mezcla de neutralidad y de sensacionalismo, de objetividad y de espectacularidad.

En la misma línea de argumentación, Corea y Lewkowicz (1999) sostienen que hay un funcionamiento hegemónico en la enunciación mediática que hace que ésta adquiera un carácter totalizador; a través de los medios se puede decir todo, se puede opinar de todo, se puede mostrar todo y se puede ver todo. La actualidad mediática se constituye en un principio de realidad social, desde el cual se generan múltiples sentidos que contribuyen a configurar el mundo que habitamos.

Por otra parte, este fenómeno de construcción de realidad mediante la producción y la circulación mediática no es una invención del siglo XX; de hecho, a partir del siglo XV, según Thompson (1998), el proceso de creación y circulación de sentido e información se modificó en la medida en que los medios de comunicación contribuyeron a la transformación de las sociedades, mediante el acceso de un mayor número de población a la información (invención de la imprenta). Para Jensen y Jankowski (1993), las sociedades modernas se configuraron a partir de la extensión y masificación de los medios; dicho acceso a la información posibilitó la difusión de nuevas formas de pensamiento, de relación y acción, de modo que muchos cambios se aceleraron. La alfabetización constituyó la condición previa fundamental para el desarrollo de la modernidad.

En este orden de ideas, en América Latina también fueron los mass media los que favorecieron el acceso de estos países jóvenes a la modernización; tal como lo expone Martín-Barbero (1991), la incorporación de las mayorías latinoamericanas a la modernidad no se hizo a través del proyecto de la ilustración, sino por vía de las industrias culturales audiovisuales, sin avanzar en lo socioeconómico, ni abandonar sus culturas orales. Los mass media: el cine, la radio, posteriormente la televisión, contribuyeron desde sus imágenes y narrativas a dar cuerpo a lo que se empezó a concebir como lo popular, reapropiando sus códigos y sus costumbres en el ámbito del espectáculo y el consumo. Hoy, la pertenencia a lo moderno, en lo que tiene que ver con la actualidad, está asociada con el acceso a los medios.

Asimismo, aunque distintos autores reconocen que el proceso de consumo audiovisual, si bien permite niveles de impugnación y resistencia (Martín-Barbero, 1991; Orozco, 1993), supone también la producción de identidades que favorecen la homogeneización cultural. Sodré (1998) da cuenta de cómo la televisión en general posibilita asociaciones e identificaciones de tipo familiar, individual y colectiva. En los discursos de las producciones teledramáticas se retoman los contextos y las vivencias heterogéneas de las audiencias, tornándose cotidianas, de modo que la televisión no se puede pensar sólo como instrumentalidad sino como generadora y organizadora del flujo de acontecimientos sociales:

La televisión se muestra capaz de producir, en su proceso de autonomía técnica, un real propio, compatible con el mercado transnacional de consumo, 
aquel que universaliza objetos de deseo. Por lo tanto, no es un mero instrumento sino mecanismo teletecnológico, en el sentido de un medio, generador de hábitos, que nos pone a disposición las alternativas del mundo aparente (p. 164).

\section{Sobre la infancia contemporánea}

Varios académicos definen la infancia como un artefacto cultural, un producto histórico de la modernidad (Steinberg y Kincheloe, 2000; Postman, 1994; Walkerdine, $1998)^{4}$, una construcción social que siempre supone una pugna por su significado (Buckingham, 2002). Estas definiciones forman parte de todo un campo de trabajo en torno a dicha construcción, donde se da cuenta del papel crucial de la familia y de la institución escolar en la estructuración de la infancia que hoy reconocemos como un referente central de afecto y protección. Así mismo, presumen que la niñez no constituye un objeto homogéneo ni universal, sino que particularidades de género, clase, etnia, región, incluso edad, conforman la diversidad de la misma.

En esta lógica, el concepto social de infancia no es una categoría biológica, sino una invención del Renacimiento que la define como condición psicológica y estructura social, que nació en el siglo XVI y se ha mantenido hasta nuestros tiempos. Según Postman (1994), en el siglo XVI, en el marco de una serie de transformaciones sumamente complejas, la comunicación empezó a tomar fuerza a través del alfabetismo social y la aparición de la imprenta, y creó un nuevo mundo simbólico al definir la adultez a partir de la exclusión inicial de los niños de los universos letrados. En este orden de ideas, para que se reconociera a la niñez como distinta de los adultos, se debió generar una nueva idea de adultez. La producción de la subjetividad infantil estuvo asociada con el surgimiento de la escuela y de la cultura letrada ${ }^{5}$.

Desde la segunda mitad del siglo XX ha tenido lugar la transformación de la infancia, en particular los modos de narrarla, ya sea como producto o a la par de los cambios en el capitalismo financiero (Carli, 2006). Alrededor de dicha transformación, algunos autores han alertado en torno a la nueva infancia que se está instaurando a partir del desarrollo de la sociedad de consumo globalizada, pero especialmente desde el acceso masivo de niños a la cultura popular mediática en las últimas décadas (Buckingham, 2002; Postman, 1994). La presencia cada vez más permanente, abarcadora y atrayente de los medios de comunicación, instalados en los escenarios privados como parte primordial de la cotidianidad, ha contribuido a movilizar o a "trastornar" la idea que se había consolidado de la infancia como

\footnotetext{
${ }^{4}$ En su mayoría estos autores retoman los aportes de P. Ariès (1987).

${ }^{5}$ Los fenómenos históricos que contribuyeron a configurar la infancia moderna no son objeto del presente escrito, razón por la cual se hace alusión al tema de manera tangencial, básicamente para mostrar al lector la movilidad que el concepto ha implicado históricamente y que en la actualidad, en particular, nos exige interrogar los elementos que inciden en la constitución de la infancia contemporánea.
} 
sumisa, frágil, heterónoma, ignorante e incluso inocente (Narodowski, 1999). Por el contrario, la infancia toma hoy los apelativos de cliente, consumidora, posmoderna, mediática, adultizada o en desaparición.

Durante las últimas décadas ha tomado fuerza la idea según la cual se ha producido un cambio radical en la manera como la sociedad significa, concibe y asume la infancia. Como consecuencia de esta noción, se evidencian un nuevo papel y un nuevo comportamiento en los niños, una nueva configuración de vida donde se les reconoce como sujetos con poder social e independencia, que en efecto logran acceder al mundo adulto cada vez con mayor facilidad. Así, se asume que los medios de comunicación son los principales responsables de la modificación de la experiencia infantil.

Steinberg y Kincheloe (2000) muestran cómo las fronteras entre niños y adultos se cruzan y se desdibujan continuamente al afirmar que la televisión permite a los niños acceder a materiales antes reservados a los adultos, y con las investigaciones de mercadeo aumentan las ofertas y las posibilidades de que los niños no se limiten a lo que se produce específicamente para ellos. Los avances tecnológicos, según Buckingham (2002), han contribuido a reforzar unos cambios institucionales y económicos en la industria de los medios, la integración de estas industrias con un mercado cada vez más dominado por monopolios o corporaciones convertidas en imperios, y las diferentes formas de fragmentación tanto en el ámbito de la producción como en el de consumo.

Estos procesos han determinado un cambio significativo en la forma de entender al niño, que ha pasado de ser vulnerable y desprotegido a consumidor soberano, influyente en lo que sus padres deciden comprar, aunque los productores de las industrias de los medios reconocen que los niños son un mercado volátil, complejo y difícil de controlar. Frente a estos análisis, Schor (2004) comprueba, en un estudio realizado sobre el consumo infantil en Estados Unidos, cómo las agencias publicitarias financiadas por las grandes corporaciones han aumentado notablemente su inversión en menores y han identificado al público infantil como un aliado importante en la promoción de los productos y en la práctica del consumo. Según Minzi (2006), la inversión en publicidad en la Argentina subió en una década más del $150 \%$, mostrando con ello la importancia no sólo de producir objetos y ofrecerlos en el mercado, sino sobre todo de producir significados: "Es en este contexto donde la publicidad -en cuanto agente discursivo del mercado- acepta una de sus mayores misiones: no sólo promocionar productos, sino modelar al niño que consume" (p. 211), aportando una nueva definición de infancia: el niño como cliente.

Como se viene anotando, varios autores hablan de la transformación en la percepción que se tiene de la infancia ligada a la fuerza de los mass media, pero que desde una perspectiva crítica remite no sólo a la modificación de unos referentes de representación, sino que supone la modificación del estatuto mismo de adultez y precipitan el desplazamiento de la definición de autonomía de sentido kantiano, al borrar las fronteras de la racionalidad y la capacidad de pensar por sí mismo, al 
simple hecho de saber diferenciar desde el gusto individual lo que se desea consumir. Así las cosas, la nueva dinámica del consumo establece otras pautas, otras relaciones y nuevas maneras de comprender la identidad y la pertenencia tanto del niño como del adulto, en tanto que la lógica publicitaria y la de mercado comercializan un mismo producto para generaciones diferentes, “creándose situaciones temáticas para un público dual de adultos infantilizados y niños precoces, convirtiéndose la edad en una mercancía simbólica al ser determinada por lo que se consume” (Kinder, 1995, citado en Buckingham, 2002, p.115).

Al respecto, Bruckner (1996) asegura que no sólo se está redefiniendo la infancia, sino también al "adulto", puesto que muchos se deleitan con la irresponsabilidad de la infancia, convirtiéndose ésta en una elección de vida, asociada al acceso de bienes y derechos sin asumir compromisos. Los jóvenes constituidos como referentes de belleza, vitalidad, actualidad, e incluso como expresión de libertad y rebeldía, son el modelo colectivo que no se duda en buscar insistentemente a través del estilo, la moda, los gustos. El estereotipo de lo joven se asume en las sociedades contemporáneas como el sueño de niños y adultos, afirmando el desdibujamiento de las fronteras entre unos y otros, y evidenciando la tendencia colectiva de juvenilización que han señalado autores ya citados (Lipovetsky, 1986; Postman, 1994; Bruckner, 1996). La publicidad y los medios en general aprovechan este interés y representan mundos en los cuales los niños pueden identificarse como mayores de lo que son (Schor, 2004).

\section{Las infancias en El rey león, Yu-Gi-Oh! y Rebelde}

La aproximación a la infancia contemporánea desde la lectura de las narrativas audiovisuales de los textos mencionados hace visible la diversidad de imágenes de infancia representadas en ellos y se constituyen en referentes, no únicos ni exclusivos, de cómo los niños construyen hoy sus subjetividades.

\section{El rey león: la corporación Disney y el mundo del consumo}

El sello Disney es un referente que identifica lo infantil. Sus personajes están presentes en los contextos educativos e incluso familiares. Muchos jardines de infantes y hogares están decorados con sus figuras, sus cuentos están entre los más leídos, las fiestas infantiles se inspiran en Disney, y sus películas se presentan frecuentemente a los niños como un premio.

Esta presencia abrumadora de Disney en la vida cotidiana motivó la reflexión sobre las imágenes de infancia que circulan en la película El rey león, por ser ésta una de las producciones cinematográficas de mayor éxito de Disney y porque aún se exhibe en los escenarios educativos, a pesar de que se estrenó en 1994.

Vale la pena señalar que un significativo número de las economías más poderosas del mundo son corporaciones. La megacompañía Disney es una de ellas. El poder 
corporativo, monopolista y expansivo de Disney es innegable debido al avance tecnológico de la época, pero principalmente por las relaciones de producción, circulación y apropiación que rigen las reglas del mercado. Según estudios realizados por la misma compañía, miles de millones de personas de todas las nacionalidades, especialmente niños, acceden a sus productos: películas, videos, programas televisivos, parques temáticos, juguetes, etc. Al respecto, Giroux (2001) plantea que el éxito mercantil de Disney evidencia el papel fundamental que la cultura del entretenimiento cumple en la organización y estructura de la sociedad actual, en los procesos de desarrollo del mundo globalizado y en la asignación de sus recursos económicos y materiales.

La corporación Disney no se limita a vender productos, ni a ofrecer entretenimiento y diversión libre de ideologías; también vende valores, imágenes e identidades que inducen a niños y jóvenes a ser consumidores. El común denominador de Disney consiste en definir "la libertad como elección del consumidor, y desnaturalizar el acontecer social mediante su reducción a puro espectáculo” (Giroux, 2001, p. 15).

La obsesión por el consumo responde a la lógica del sistema actual. Como bien anota Bruckner (1995), el consumismo ha llevado a los hombres a que se sometan a las cosas, creando una cultura de la circulación de éstas, las cuales tienen la virtud de lo efímero pues pasan apresuradamente de moda, al tiempo que se imponen otros que se adquieren para usar, desechar y volver a comprar. Disney crea y reproduce esta dinámica, utiliza la diversión, la ternura, la recuperación de sueños, para convertir a cualquier niño en un consumidor permanente de sus ideas y productos. En palabras de Barsy (1998), los personajes de Disney "hoy son construcciones autónomas que no necesitan el referente de la realidad para interactuar con ella. Universalizados en la psique colectiva por los medios masivos de la cultura del entretenimiento, ni siquiera necesitan hacer para ser" (p. 40).

Walt Disney se caracteriza por producir principalmente películas de dibujos animados, técnica que consiste en crear la ilusión de que los animales, dibujos, muñecos u objetos estáticos tienen movimiento propio y sentimientos; en otras palabras, se humanizan. La estrategia publicitaria consigue impactar a las audiencias, de modo tal que su último estreno generalmente logra ocupar los primeros lugares en ventas, no sólo de la película promocionada, sino también de sus nuevos personajes, impresos en camisetas, juguetes, discos, etc.

Las producciones cinematográficas trasladan a los niños y niñas a lugares exóticos y extraños, ricos en fantasías, aventuras románticas y temas con bastante emotividad sobre supervivencia, separación, muerte, pérdida de seres amados; sus personajes remiten a oposiciones marcadas: son buenos o malos, ricos o pobres, bonitos o feos, blancos o negros. Presentan un escenario cinematográfico colorido, con música contagiosa, diversidad de planos, ambientaciones que remiten a lo natural.

En la trama de las películas no se plantean rupturas con el orden establecido, se aceptan el poder y la dominación como algo natural; parafraseando a Giroux 
(2001), éstas tienen una fuerte ideología reaccionaria, fomentan una visión de mundo conservadora, en una puesta en escena que proporciona alegría y placer. En los mensajes culturales transmitidos se promueven el racismo y el sexismo. Los niños pueden aprender construcciones de género de las producciones cinematográficas; "los roles de las niñas están subordinados a los masculinos y sus deseos son casi exclusivamente en términos de narrativa del macho dominante" (p. 107). Los estereotipos raciales y de clase son otro tema recurrente y se presentan de manera sutil: se ridiculiza y estigmatiza a los indios, latinos, árabes, negros, al ser asociados a la maldad, la miseria o la simplicidad. El clasismo es inherente a Disney tanto como el placer. Es más, podría decirse que estas son las características que lo definen.

\section{El rey león: el orden instituido y la infancia estereotipada}

En la historia se cuenta cómo la ambición del poder lleva a Scar, el personaje antagónico, a precipitar la muerte de su hermano, el rey Mufasa. Scar culpa y expulsa a Simba, el legítimo heredero al trono, usurpando su poder y llevando el reino a la decadencia. Simba crece lejos del dominio de Scar, al lado de Timón y Pumba, cuyo lema es Hackuna Matata, "olvídate de toda preocupación”; sin embargo, para reinstaurar el orden Simba regresa a ocupar su lugar expulsando a Scar, quien muere atacado por las hienas. Luego todo vuelve a la normalidad. Simba retoma el poder, el cual se perpetúa con el restablecimiento de la familia real (Simba y Nala) y el nacimiento de un nuevo heredero.

En la película se muestra que en la sociedad hay unas relaciones de poder que siempre hay que respetar: las ceremonias de los bautizos (de Simba y de su hijo) se celebran en días resplandecientes, los colores son brillantes, la música hermosa; todos los animales en condición de absoluta inferioridad acuden al llamado del rey, que los mira desde lo alto, muy orgulloso. Todo es armonía y felicidad porque nace un futuro rey; la autoridad del monarca es incuestionable.

Lo anterior sugiere una ideología que legitima las relaciones de poder verticales. Nos dice que el poder es hereditario, está predeterminado, nadie puede usurparlo, y el que se atreva sufre las consecuencias; esta idea se refleja en las escenas del reinado de Scar, donde los colores son oscuros, los rostros muestran inconformismo, hay miseria; al final, muere repudiado. La figura de Scar marca lo oscuro, lo considerado malo, pero cuando Simba asume el poder, se restaura el colorido, el verde de la selva es más intenso, todos se ven felices.

Otra condición que se trata de perpetuar y validar en El rey león es la estratificación social. Desde la primera escena, la diferenciación de las clases sociales es evidente: en el plano general, la realeza está ubicada en la cima de la roca del trono y los demás en un plano inferior. La familia real representa una elite "blanca”, o con pureza, en cuanto no tiene mezclas ni texturas de piel distintas de la propia de la especie, mientras que las hienas y Scar, león negro de la familia, representan el mestizaje, la impureza y, por esa vía, la maldad. Al bautizo no pueden asistir las hienas, 
quienes habitan la periferia, el cinturón de la miseria; estos personajes se presentan en la cinta como antagónicos, lo cual, desde el punto de vista de lo real, sugiere el pánico hacia lo marginal, que se asocia con la pobreza y con los personajes que la encarnan. Rivera (2004) anota que en la película en inglés, las hienas tienen acento afroamericano, y en español, uno mexicano; podría entenderse que las hienas representan los peligros de los potenciales inmigrantes. Por otro lado, en El rey león se presenta una clara asignación de roles masculinos y femeninos; lo femenino es representado en las leonas Sarabi y Nala, quienes se muestran frágiles, románticas, dependientes y no desempeñan papeles protagónicos, en tanto que los masculinos, Mufasa, Simba joven y el propio Scar, son los fuertes, los que toman decisiones; incluso, quien educa es el padre. El papel maternal en la película es secundario, instaurándose como legítimo el orden patriarcal.

Asimismo, en la película se destacan especialmente la diversión, el ocio, el mundo infantil: Simba como cachorro expresa la ternura, lo intrépido, lo curioso, pero también la debilidad, la sumisión, la ingenuidad. Se muestran relaciones de cariño y cuidado, específicamente paternales (Mufasa-Simba), el peligro está fuera de dichas relaciones y de los límites definidos como seguros por la autoridad paterna; en los territorios considerados peligrosos, el cachorro es protegido por los cercanos (Sazu, Mufasa, Timón, Pumba, protectores incondicionales de Simba), evidenciando la fragilidad, dependencia e incapacidad de Simba para asumirse autónomamente. Esta historia trata de la idea de infancia "normal", del deber ser, entendida como la producida en familias de clase media, occidental: una imagen de niño estereotipado, que busca ante todo preservar los privilegios de la diversión, la protección, la dependencia. La diversión se presenta como sinónimo de felicidad: Timón y Pumba representan el placer sin compromisos ni límites, el hedonismo total, se reivindican cantando constantemente "Hackuna Matata". Estos personajes no son fuertes, ni tampoco inteligentes ni trabajadores; sin embargo, son los más queridos y recordados de la historia, en cuanto son una invitación abierta al conformismo y la diversión. Al respecto, Bruckner (1995) señala:

El consumismo y la industria de la diversión son una creación colectiva extraordinaria sin equivalente en la historia. Por primera vez, los hombres borran sus barreras de clase, de raza, de sexo, y se funden en una única multitud dispuesta a aturdirse, a divertirse sin pensar en nada más (p. 71)

Continúa diciendo este autor que con esos templos de la vida alegre, de esa felicidad y diversión que pregonan los medios, el ser humano se libra de la historia, de su propia historia, olvida las opresiones y sus miserias.

En síntesis, lo que la película intenta conservar es el tradicionalismo de una sociedad patriarcal, desigual, hegemónica, con las injusticias, exclusiones y segregaciones que esto implica. Desde dicha perspectiva, la cinta otorga sentido a lo ciudadano: sujetos sociales acríticos, conformistas, sumisos, lo cual se expresa en un interés por la conservación del poder y del orden instituido, situando una idea 
de niñez consumidora por excelencia, donde su mayor necesidad es la diversión y el placer.

\section{Yu-Gi-Oh!: la infancia salvadora, autosuficiente y competitiva}

Se analizó la serie televisiva $Y u$-Gi-Oh! Duelo de monstruos ${ }^{6}$ dado el alto nivel de aceptación que tenía entre los niños, expresada en los juegos dramáticos y en el juego de cartas que se promocionaron paralelamente con la emisión del programa, mediante los cuales se invitó a los menores a participar de manera indirecta en la trama misma, a través de la creación de sus propios duelos de monstruos.

Esta serie pertenece al género anime, nombre dado por los escritores y dibujantes japoneses al tipo de animación hecho en su país, que se destaca por su expresividad, la intensidad de las historias contadas, el manejo virtuoso de las figuras y las sombras. Su dibujo inconfundible y su fina elaboración técnica han convertido al anime en un elemento de la cultura pop japonesa, con gran aceptación en Occidente. Dentro del anime existen subdivisiones temáticas, como comedia, romance, artes marciales, historia, pornografía, ciencia-ficción, etc.

El anime Yu-Gi-Ob! apareció en la televisión japonesa en 1996, con una primera temporada de 27 capítulos sin el éxito comercial esperado. No obstante, empresas como Konami y Nintendo, con el juego de cartas y los videojuegos del anime, respectivamente, impulsaron la segunda temporada con el título Yu-Gi-Ob! Duelo de monstruos. Las animaciones, gráficos y diseños de los personajes mejoraron sustancialmente y su audiencia aumentó en forma considerable, extendiéndose incluso a otros continentes. La versión de anime de Yu-Gi-Oh! Duelo de monstruos se convirtió en un éxito inmediato.

Aunque los dibujos tienden a guardar el formato del kodomo, género de anime dirigido al público infantil y en el cual los personajes no tienen un diseño muy elaborado y los escenarios son sencillos en su forma pero muy creativos en el diseño, la serie no puede clasificarse exclusivamente en este género, pues conserva características de otros como el shônen (historias dirigidas a los públicos jóvenes que gustan de la acción y las aventuras) y, de cierta manera, de la fantasía heroica.

La trama de la serie se centra en la lucha de su personaje principal, Yu-Gi, por recuperar los siete artículos del milenio, dentro de los cuales están guardados poderes nefastos que amenazan con destruir el mundo. Yu-Gi resuelve el secreto de uno de los artículos (el rompecabezas del milenio), en el cual está encerrada la presencia del emperador Yami Yu Gi. Al hacerlo, desencadena la liberación de todas las fuerzas oscuras contenidas en los artículos, con lo cual se pone en riesgo la paz del mundo. Para restablecer el orden, el emperador se encarna en Yu-Gi y se constituye en su álter ego, otorgándole un gran poder que, junto con su confianza en el corazón de las cartas, le da la fuerza necesaria para enfrentarse con rivales difíciles y vencerlos.

\footnotetext{
${ }^{6}$ Esta temporada fue emitida en Colombia entre 2004 y 2005.
} 
La historia se mueve entre espacios reales y espacios imaginarios o mentales traídos a la realidad por medio del juego de cartas. La mayor parte de la serie se desarrolla en las arenas de duelo, en las que se activan los monstruos de las cartas que van emergiendo del tablero de juegos. En las peleas de estos monstruos parece haber contacto de energías y no de cuerpos. Mediante el juego los personajes se trasladan a lugares distantes, como Egipto, por ejemplo, con sus excavaciones, pirámides y tumbas. Las puertas conducen de un escenario a otro completamente diferente, como si a través de ellas se cambiara de dimensión, de lugar y de tiempo.

El espacio es móvil y hay una ruptura con la linealidad del tiempo. De acuerdo con Corea y Lewkowicz (1999), el uso del lenguaje cinematográfico es el que permite manejar las anticipaciones y las retrospecciones que demanda del público infantil, competencias de mayor complejidad para su comprensión. Así, en la serie, pasado y futuro aparecen simultáneamente. Aunque los personajes son futuristas, viajan al pasado egipcio, que parece revivirse a través de los dramas de la época. Trae lo místico a la actualidad. De la misma manera, sueño y realidad parecen mezclarse. El poder obtenido en el juego incide en el poder en la vida real de los personajes.

No se evidencian formas de pensamiento dual tan fuertemente arraigadas como en Occidente. Hay más bien una transmutación de un elemento en su opuesto. Así, la belleza puede transmutar en fealdad o la bondad en maldad, en un mismo ser. Nada es porque sí. Todo tiene una razón de ser en relación con la dinámica de la vida misma. Lo moderno está anclado en lo tradicional. Por medio de la historia contada se recrea un pasado milenario, un poder ancestral con los adelantos tecnológicos y los mundos virtuales.

La época representada corresponde al siglo XXI por el protagonismo de las tecnologías. Asimismo, se puede observar la destreza de los personajes infantiles en el manejo de éstas. Buckingham (2002) llama la atención sobre la necesidad de reconocer que las diferencias generacionales en el uso de las nuevas tecnologías no son producto exclusivamente de la tecnología misma, sino el resultado de la conjugación de diversas fuerzas sociales, históricas o culturales.

En Yu-Gi-Ob!, frente a la noción de infancia vulnerable, desprotegida, frágil y heterónoma, se erige la idea de la infancia salvadora, más capaz incluso que los mismos adultos. El esfuerzo permanente de éste y sus amigos consiste en evitar que fuerzas malignas se apoderen de su mundo, desde la premisa de que la realidad que viven ya constituye un orden que no se debe transgredir. Se privilegian situaciones en las cuales los adultos son vulnerados y violentados: así, Yu-Gi desarrolla toda una estrategia de juego en compañía de sus amigos para salvar el alma de su abuelo, Muto, denotando acciones de protección y apoyo de los niños hacia los adultos, presentados estos últimos como incapaces y frágiles, trastocando de esta manera una noción fuertemente instaurada sobre los adultos, como aquellos que definen el orden y los limites. Por otra parte, en la serie se minimiza la imagen adulta; son personajes secundarios, tienen los mismos intereses que los niños pero con menor 
poder. Están tan presos del poder de las cartas como los mismos niños, pero a su vez son menos capaces de dominar el juego.

$\mathrm{Al}$ respecto de este desdibujamiento de los papeles asumidos tradicionalmente por niños y adultos, Arendt (1996) llama la atención sobre la tendencia creciente a igualar o borrar en la medida de lo posible, las diferencias entre jóvenes y viejos, niños y adultos, alumnos y maestros, al suponer que

(...) existen un mundo y una sociedad infantiles ambos autónomos, por lo cual han de entregarse a los niños para que los gobiernen. La autoridad que dice a cada niño qué tiene que hacer y qué no tiene que hacer, está dentro del propio grupo infantil y esto produce una situación en la que el adulto como individuo, está inerme ante el niño y no establece contacto con él (p. 192).

Esta pérdida de contornos la refuerzan los medios a través de estrategias de mercado que posicionan con firmeza ese universo infantil autosuficiente frente a un adulto que cede cada vez más terreno y pierde más autoridad. En este sentido, siguiendo el argumento de Minzi (2006), para configurar un universo infantil cargado por sí mismo de contenido y fuerza, los productos dirigidos a la población infantil necesitan construir un otro, un distinto, un opuesto que cohesione el "nosotros" niños. Si los niños son los protagonistas, los diferentes, los opuestos, los actores secundarios por correlato son los adultos: "La invisibilización del adulto y la deslegitimación de su autoridad son los sustentos de una representación de infancia que apuesta a seducir a los consumidores jugueteando con el deseo de autonomía, tan a flor de piel en esa etapa de la vida” (p. 226).

Sin embargo, esta postura adultizada también resulta ambigua en la medida en que se aspira a jugar con la irresponsabilidad del niño en el sentido de que no asume sus actos conscientemente, pero a la vez aspira a tener la autonomía de los adultos. Esta es la conjugación perversa que alude a la idea de quiero ser libre, pero que alguien se encargue de mi (Bruckner, 1996).

En las relaciones adulto-niño se subvierte el orden instituido, la familia presentada en la serie no corresponde a la tradicional. Aparece como un telón de fondo, marginal, donde las figuras paternas y maternas están casi ausentes. Los amigos son los auténticos referentes de afecto. Se quiere mostrar la capacidad de los niños para entablar amistades fuertes, a través de las cuales se espera conquistar el mundo y triunfar en los propósitos. Con todo, esto revela igualmente la soledad de los niños, absorbidos por el juego y las tecnologías, sin que sus padres se percaten de ello.

En la serie, aunque en apariencia predominan la unidad y el esfuerzo mancomunado, lo que en realidad se deja ver es una idea de lo colectivo utilitaria y opacada por el sentido de liderazgo. Se trabaja en equipo no para un beneficio común, sino para que el líder logre sus propósitos; por tanto, alcanzar poder es lo importante, la amistad es sólo una estrategia. La unión y la camaradería cobran sentido para atacar y vencer al enemigo. Así mismo el lenguaje está cargado, de manera reiterativa, de un sentido de confrontación: son frecuentes términos como poderoso, rival, fuer- 
za de ataque, destrucción, defensa, sacrificio, el elegido, poder infinito, que ponen en escena el antagonismo y las tensiones que son elementos centrales en la serie.

La infancia representada en la serie $Y u$-Gi-Ob!, corresponde de algún modo a lo que Narodowski (1999) ha denominado como hiperrealizada, caracterizada por la demanda de inmediatez contenida en la misma cultura mediática y una facilidad sorprendente para dar cuenta de los nuevos desafíos tecnológicos, superando con creces a los adultos.

\section{Rebelde: la juvenilización de la infancia}

Las transformaciones latentes de la infancia contemporánea se asocian, según algunos autores, con la consolidación de un agente socializador infaltable en los hogares: la televisión. Por este medio circulan relatos que se constituyen en horizontes de significación, incorporados por los niños como parte central de sus vidas.

La telenovela es el producto más importante de la industria cultural televisiva. El relato que propone, posibilita la construcción de sentidos individuales y colectivos a través de la relación de consumo, donde tanto productores como consumidores son capaces de establecer una conexión de sentidos y hasta de intereses: los primeros no son ajenos a las expectativas y realidades del público, y los segundos encuentran en los medios no sólo una parodia de sus vivencias, sino sus anhelos reflejados y sus sueños cumplidos (Martín-Barbero, 1992).

En esta perspectiva, se puede afirmar que la telenovela es uno de esos relatos que permiten seguirles la pista a esos nuevos significados que se están instalando en la construcción social y cultural de la infancia. Al respecto, la serie Rebelde $e^{7}$ sirve de pretexto para hacer una aproximación al análisis de la tendencia de la sociedad contemporánea a posicionar "lo juvenil" como el icono ideal en la constitución de sujetos, en particular de la infancia. Algunas de las evidencias asociadas a este fenómeno tienen que ver con el fin de la autoridad adulta y el poder paterno, la omnipotencia del deseo "todo aquí y ahora mismo" (Bruckner, 1996), la imposición de un estilo, los niños asumidos como los principales socios de las empresas comerciales, etc.

En octubre de 2004 salió al aire la primera temporada de la telenovela juvenil Rebelde, una adaptación mexicana de la serie original Rebelde way, emitida en Argentina. El éxito de la versión mexicana, producida por Televisa, desbordó todas las expectativas del mercado internacional, convirtiéndose en un icono de consumo televisivo en América Latina y la comunidad de habla hispana en Estados Unidos.

Rebelde trata de un grupo de adolescentes que estudian en el Elite Way School, un internado mixto, reconocido como uno de los mejores colegios para las clases más ricas y poderosas de México. La historia se articula alrededor de la creación y consolidación del grupo musical RBD, que no sólo es el eje de la trama sino que se

\footnotetext{
${ }^{7}$ Rebelde no es, en sentido estricto, una telenovela, pero incorpora claves argumentales propias del género.
} 
convierte en un producto con vida propia fuera de la telenovela, sus temas musicales inundan las emisoras y ganan adeptos que quieren parecerse a los personajes de la serie que conforman el grupo musical.

El mundo de lo juvenil, puesto en escena a través de la combinación de rebeldía, música, moda, baile, le da a la serie un clima dramático novedoso que contribuye a transformar el formato de la telenovela tradicional, generando identidades y complicidades con el público, que se siente representado. Esta mixtura del formato plantea nuevos contenidos y propuestas estéticas al melodrama, en cuanto logra conectar historias, subjetividades y contextos sociales de distintos personajes que sostienen un flujo narrativo complejo, atrapando el interés del público.

Sin embargo, el éxito de Rebelde no sólo tiene que ver con una trama cercana a la vida cotidiana de los adolescentes; es también el resultado de una estrategia de mercado dinámica, mediante la cual se puso en marcha toda la infraestructura comercial y publicitaria de Televisa y de los canales privados locales que compraron los derechos de transmisión, para posicionar la serie en las franjas infantiles y juveniles.

En el caso colombiano, la masiva acogida de Rebelde, especialmente entre los niños, incentivó el cambio de horario de transmisión de la serie: de media hora diaria de lunes a viernes, a la franja infantil de los fines de semana, en reemplazo de dibujos animados y otras ofertas. Este seriado juvenil alcanzó una emisión cercana a las cinco horas semanales, situándolo en el primer lugar de las preferencias televisivas del público infantil colombiano.

Es evidente que para el discurso televisivo el criterio de edad como principio que separa los receptores de la telenovela desaparece; por encima de esta consideración, lo que predomina es una política de marketing de los canales comerciales que definen como el receptor ideal de sus programas a los sujetos entre 5 y 25 años de edad. En el discurso mediático lo que cuenta es ser joven o adolescente, no en la perspectiva de la edad como rasgo distintivo sino como imagen de juventud; en principio, cualquiera que se precie de ser joven es un potencial consumidor televisivo (Corea y Lewkovicz, 2004). En este esquema se borra todo límite entre generaciones, por lo que una serie como Rebelde se produce para cualquiera que corresponda al imaginario de lo joven.

Adultos y niños son invisibles en la trama de la telenovela. Los primeros, a pesar de aparecer en las escenas, son actores marginales, ignorados o ridiculizados, y los segundos están físicamente ausentes en casi todo el desarrollo de la trama. No obstante, la ausencia en escena no impide que las historias contadas representen mundos de vida juveniles que sirven de referentes para el público que sigue la serie, en cuanto nutren y alimentan con significados los sueños, los ideales y las formas de existir de los sujetos. 


\section{La vida a contracorriente: el modelo ejemplar}

La trama plantea sutilmente la confrontación entre los adolescentes y las dinámicas sociales que los producen. Este esquema de confrontación estructura un tejido argumental donde el concepto de rebeldía es el eje articulador de las decisiones, las acciones e interacciones de los protagonistas; desafiar la autoridad y las normas establecidas, ir contra la corriente define el carácter de los personajes juveniles de la serie. La tensión que resulta propone un escenario donde el orden instituido se desmorona. El andamiaje social normatizado se agota ante el ímpetu juvenil que se reinventa permanentemente y desborda las marcas previas que lo contienen.

La vida de los adolescentes se pone en un escenario que restringe, que vigila pero a la vez ofrece las posibilidades para la evasión o para la infracción. Constantemente, los jóvenes logran frustrar los planes de disciplinamiento tanto de los profesores como del director, cuya autoridad resulta marginal e insulsa. Aunque los jóvenes protagonistas sean "cachados o pillados", la historia propone una salida airosa para el infractor. Muchas veces, en su propósito de transgredir el orden instituido logran la colaboración de padres y maestros, que para proteger a los jóvenes del rigor de la norma o ayudarlos en sus propósitos de retar los códigos impuestos por la directiva institucional, se convierten en cómplices de la desobediencia.

Si bien el escenario de la trama está propuesto con medidas disciplinarias y coercitivas, lo que allí acontece hace eco a lo que Lipovetsky (1994) describe como la tendencia de la sociedad contemporánea a reducir la rigidez de las organizaciones, a flexibilizar las relaciones y privilegiar la comunicación sin coerción.

En relación con el tiempo, la historia muestra un presente intenso. Las evocaciones del pasado justifican las acciones del presente y las referencias al futuro son sólo para no olvidarse del mañana. Se muestran adolescentes sin arraigos profundos en tradiciones, lo que resulta evidente en su apropiación ambigua: si se consideran pertinentes para su beneficio, valen; de lo contrario, se desechan, se pelea contra ellas o se esconden, porque lo que importa es la realización personal, anclada en la idea de satisfacción inmediata de los deseos, en la premisa de vivir intensamente el hoy.

Los mundos de vida juvenil que propone Rebelde son mundos seducidos por la idea de felicidad como legítima aspiración al bienestar individual. En el caso de la serie, ser Rebelde se relaciona con la posibilidad de satisfacer de inmediato los caprichos y demandas de libertad de los jóvenes. Las situaciones de la serie muestran a los jóvenes evadiendo el marco normativo de la institución, sin la intención de dañar; sus travesuras no tienen maldad. Parece que sus acciones son inocentes, pues sólo buscan reparar, hacer justicia, reivindicar el amor o simplemente ser rebelde, como pregona el coro del tema musical de la serie:

Y soy rebelde cuando no sigo a los demás

y soy rebelde cuando te quiero hasta rabiar

y soy rebelde cuando no pienso igual que ayer 
y soy rebelde cuando me juego hasta la piel

si soy rebelde es que quizás nadie me conoce bien.

Son reivindicaciones que liberan del deber, la espera, la maduración, la contención y todo lo que tenga que ver con preocupaciones y responsabilidades (Bruckner, 1996).

El bienestar individual se asocia con la posibilidad de acceder a las comodidades que eliminan las diferencias materiales y crean las condiciones de la felicidad, para que cada cual intente "no ser como los demás"; esto es, ser alguien entre la multitud a través de la compra de los objetos o de los estilos de vida que dan la posibilidad de hacer la diferencia. En este orden de ideas, las vidas de los personajes de Rebelde fluyen como si no existiera oposición entre ricos y pobres. La trama resuelve las diferencias ofreciendo un espacio de confort que todos disfrutan por igual. La relación con el dinero y la solvencia que algunos personajes expresan, las acciones de consumo explícito de atuendos y objetos diversos (regalos como televisores, muñecos, relojes, autos, etc.) circulan en la serie sin que se explicite el origen de los ingresos en el sentido de la materialidad laboral y comercial que implica su obtención. En la cotidianidad del internado, los personajes intercambian productos que se venden en el mercado, como papas fritas y otros. Los escenarios confortables y la ausencia de preocupaciones económicas legitiman la relación entre bienestar, poder y consumo como indisociable, y este último como determinante de lo anterior.

En este punto cabe la reflexión de Sodré (1998), quien sostiene que cuando en las telenovelas pobres y ricos están en el mismo escenario, no como antagónicos sino como privilegiados, empieza a circular la ilusión de participación equitativa en los beneficios del mercado y de la riqueza; se pone en escena el sueño de las audiencias de una distribución de las "ventajas" de la riqueza que facilitan el acceso a ese bienestar material que promete la felicidad.

\section{La fluidez del vínculo familiar: los padres malos}

En Rebelde se muestra una familia en transición, con relatos diferentes de la herencia española, que enarbolaba la familia monogámica y patriarcal como el único modelo posible de convivencia familiar. Aunque el modelo tradicional coexiste con otras formas de ser familia, en la trama predomina un orden familiar distinto del instituido; aparece una configuración nueva:

Los padres reconocen ciertos deberes para con sus hijos: pero no hasta el punto de permanecer unidos toda la vida y sacrificar su existencia personal (...) Ya no se respeta la familia en sí, sino la familia como instrumento de realización de las personas, la institución "obligatoria" se ha metamorfoseado en institución emocional y flexible (Lipovetsky, 1994, p. 162).

En un análisis complementario, Corea y Lewcovicz (2004) señalan que el mercado ha producido realidades asentadas sobre la fluidez, y en la fluidez las conexiones son contingentes. En el caso de la familia representada en Rebelde, no hay un 
andamiaje estructural que la soporte, "el vínculo se sostiene sobre prácticas efectivas y no en un sistema clasificatorio, no en una institución. El vínculo se sostiene por haberse elegido mutuamente, por cuidarse, acompañarse, no porque haya un anclaje dado de antemano sino porque el haberse encontrado produce un entorno significativo" (p. 113).

En cuanto a las nuevas relaciones que surgen en estas formas de existencia de la familia, la serie muestra un debilitamiento de los deberes de los hijos hacia sus progenitores: "ya no se educan niños para que honren a su padres sino para que sean felices, para que se conviertan en individuos autónomos, dueños de sus vidas y de sus afectos" (Lipovetsky, 1994, p. 164), mientras que los deberes de los padres hacia sus hijos se refuerzan, pues el mandato es cuidar, acompañar y subsidiar a sus hijos; de lo contrario, se les castiga: "Ya no hay niños malos, sólo padres malos" (p. 165).

La familia que proyecta Rebelde no responde a la solidez de la institución familiar que contribuyó a definir al niño moderno protegido y dependiente, sino aquella en la que los pares, la televisión, los videojuegos, y en general el universo mediático, conforman los soportes afectivos de los nuevos niños-jóvenes.

\section{La infancia en las narrativas audiovisuales}

Las representaciones de la infancia contemporánea expuestas en las narrativas mediáticas analizadas atienden a nociones de infancia no unívocas, ni homogéneas, sino móviles y complejas, en las que se entremezclan visiones modernas de fragilidad e inocencia con aquellas donde lo intrépido, la capacidad de resolución y el saber se plantean como propiedad de los niños y los adolescentes.

La edad es otra categoría que se moviliza en cuanto los sujetos presentes en los textos son fundamentalmente jóvenes y adolescentes, que sirven como referente de identificación para los niños y remiten a una niñez adultizada o a una adultez juvenilizada; por tanto, los papeles se invierten, ya que los niños aspiran con creciente ansiedad a la libertad que supuestamente reside en la juventud, y muchos adultos se deleitan con la irresponsabilidad de la infancia, razón por la cual la juventud se convierte en una elección de vida.

Otro aspecto relevante es la imagen de la infancia que se transforma desde la perspectiva mediática, lo cual está asociado con procesos de conservación, de movilidad y de reorganización, que no supone cambios absolutos, de un modo estable a otro, sino que implica la fluidez con que la categoría infancia se adapta, se desplaza, toma forma en los contextos particulares en los que se produce, de acuerdo con las presiones que ejercen tanto las audiencias como los mismos creadores del mundo audiovisual.

Si bien no se afirma que los niños apropien literalmente lo expuesto por los medios, sí se insiste en la carga simbólica de las imágenes transmitidas por las nuevas educadoras del siglo XXI: las industrias culturales. Las propuestas de los medios se incorporan a la psiquis colectiva mediante fórmulas repetitivas sobre el deber ser 
del confort y del bienestar individual. Los medios contribuyen a la producción de imágenes de infancia que funcionan como referentes identitarios y guías de acción individual y colectiva.

Por último, la producción mediática presenta un mundo de igualdad, en el que no se reconocen la heterogeneidad de la población infantil ni el conflicto. Las narrativas audiovisuales contempladas producen una imagen estereotipada de la niñez, creando una idea de normalidad en la que el esquema confortable de la clase media se constituye en modelo y realidad única, invisibilizando las desigualdades y diferencias de una sociedad en la que un alto porcentaje de la población está en condiciones de miseria. Se uniformiza a la población infantil en una idea dorada de felicidad e igualdad, quitándoles sentido a las problemáticas que la aquejan, así como a la referencia a sus derechos y a las reivindicaciones al respecto.

\section{Más allá de los textos audiovisuales}

En la perspectiva de Buckingham (2002), la intertextualidad se ha convertido en una característica dominante de los medios actuales que refleja el creciente proceso de convertir todo en mercancía y la necesidad de explotar los éxitos a través de una amplia gama de estrategias, en el menor tiempo posible. En este sentido, los textos analizados son además videojuegos, películas, cartas de juego, álbumes, afiches, camisetas, loncheras, juguetes, entre otros. Esta característica textual demanda la existencia de un lector idóneo, que maneje los elementos básicos de la trama y asuma, en palabras de Corea y Lewkowicz (1999), una implicación subjetiva con el texto y un mayor esfuerzo interpretativo del que exigiría el relato lineal. Pero más allá de las habilidades interpretativas que exigen este tipo de textos, está la alianza entre producción y consumo, entre medios y marketing, que responde a la lógica del sistema social actual, caracterizado por la preponderancia de lo efímero frente a lo duradero, de lo individual frente a lo colectivo, de la competencia frente a la cooperación.

Tanto Yu-Gi-Oh! como Rebelde se emiten en el marco de lo que implica la cotidianidad televisiva, en la cual se integran contenidos comerciales a los de las series como tal, en un flujo de imágenes conectadas por la lógica del consumo. Las franjas publicitarias son bastante extensas y se incorporan al flujo televisivo sin generar rupturas con los contenidos desarrollados en las series; de este modo se construye un nexo entre textos mediáticos específicos y productos publicitados, que remiten sin contradicción a un discurso que fluye y va de la serie $\mathrm{Yu}-\mathrm{G} i$-Ob! a las cartas, a los videojuegos, y del teledrama Rebelde a los discos, los atuendos, los pósteres, y de la película $\mathrm{E}$ l rey león a los muñecos, las loncheras, las camisetas, los cuentos para colorear y los combos de hamburguesas. 


\section{Preguntar por las narrativas audiovisuales es preguntar por la sociedad actual}

Cómo decir de otra manera lo que todos sabemos y repetimos constantemente; cómo insistir en que lo aparente y obvio no esconde ninguna verdad más allá de lo que se hace visible, pero que nos cuesta ver; el presente artículo nos permite aproximarnos a la comprensión de esa verdad que está latente.

Los relatos audiovisuales, en general:

- Responden a fenómenos de la contemporaneidad, apuestan por la homogeneización de los sujetos en el marco del mercado, donde el individuo es rey y la principal evidencia de bienestar es el consumo.

- Apelan, cuando están dirigidos a los niños, a la idea de inocencia, diversión y placer como propios y exclusivos del mundo infantil, con contenidos problemáticos, de tipo sexista, clasista, colonialista, consumista.

- No son uniformes, ni persiguen los mismos ideales, como si se tratara de una fuerza compacta; por el contrario, se constituyen en motivo de pugna y de debate, configurando de manera contradictoria modos de ser sujeto.

- Son una agencia fundamental, no la única, en la construcción de lo social al incorporar los deseos, las preguntas, los ideales de los sujetos, elaborando desde allí un deber ser articulado a la lógica del capitalismo financiero.

- Son grandes relatos, que en conexión con los de la publicidad, el mundo de la calle y el mundo de la vida, conforman fuentes importantes desde donde se interpreta y se actúa en la cotidianidad.

Finalmente, es clave que las sociedades globalizadas y los sujetos que las conforman, cuestionen el lugar en el que han puesto a los medios y la importancia que les conceden en la producción de significaciones sobre el mundo. En esta perspectiva, no basta con responsabilizar a los medios de la crisis de lo instituido, incluso de lo asociado con la desaparición de la idea de niñez moderna; es necesario que se asuma la complicidad e indiferencia con las cuales se instala lo mediático en la vida personal y colectiva, y se permite su centralidad en la configuración del presente. 


\section{Bibliografía}

Arendt, H. (1996). Entre el pasado y el futuro. Ocho ejercicios sobre la reflexión política. Barcelona: Península.

ArIÈs, P. (1987). El niño y la vida familiar en el antiguo régimen. Madrid: Taurus.

Barsy, K. (1998). Disney World. Viaje a otra dimensión. El Malpensante, 9, 40.

Bienal Iberoamericana DE CoMUNICACIÓN. (6: 2007). Narrativas audiovisuales. Consultado el 29 de julio de 2007 en http://www. bienaldecomunicacion.org/default3. asp? sec $=221 \& \operatorname{secp}=201 \&$ id $=45$

BRUCKNER, P. (1996). La tentación de la Inocencia. Barcelona: Anagrama

Buckingham, D. (2002). Crecer en la era de los medios electrónicos. Tras la muerte de la infancia. Madrid: Morata.

CARLI, S. (2006). Notas para pensar la infancia en la argentina (1983-2001). Figuras de la historia reciente. En S. Carli (Comp.). La cuestión de la Infancia. Entre la escuela, la calle y el shopping. (pp. 19-54). Buenos Aires: Paidós.

Corea, C. y Lewkowicz, I. (2004). Pedagogía del aburrido. Escuelas destituidas, familias perplejas. Buenos Aires: Paidós

Corea, C. y LewKowicz, I. (1999). ¿Se acabó la infancia? Ensayos sobre la destitución de la niñez. Buenos Aires: Lumen-Hvmanitas

Giroux, H. (2001). El ratoncito feroz. Madrid: Fundación Germán Sánchez.

GIROux, H. (1990/1997). Los profesores como intelectuales. (1. ${ }^{a}$ reimpresión). Barcelona: Paidós.

Jensen, K. y Jankowski, N. (1993). Metodologías cualitativas de investigación en comunicación de masas. Barcelona: Bosch.

Lipovetsky, G. (1994). El crepúsculo del deber. Barcelona: Anagrama.

Lipovetsky, G. (1986). La era del vacio. Barcelona: Anagrama

Martín-Barbero, J. (1991). De los medios a las mediaciones. Comunicación, cultura y hegemonía. México: Gustavo Gilli.

Martín-Barbero, J. y MuÑOZ, S. (1992). Televisión y melodrama. Géneros y lecturas de la telenovela en Colombia. Bogotá: Tercer Mundo Editores.

Minzi, V. (2006). Los Chicos según la publicidad. Representaciones de infancia en el discurso del mercado de productos para niños. En S. Carli (Comp.). La cuestión de la infancia entre la escuela, la calle y el shopping. (pp. 209-240). Buenos Aires: Paidós.

Narodowski, M. (1999). Después de clase. Buenos Aires: Novedades Educativas. 
Orozco, G. (1993) Televidencia y mediaciones. La construcción de estrategias por la audiencia. En G. Sunkel. (1999). El consumo cultural en América Latina. Bogotá: Convenio Andrés Bello.

Postman, N. (1994). The disappearance of childhood. New York: Vintage

Rivera, J. (2004, Agosto, Septiembre). El ciclo sin fin: una mirada a $E l$ rey león desde la lectura de la imagen. Razón y palabra, 40. Consultado el 20 de noviembre de 2006 en http:// www.razonypalabra.org.mx/anteriores/ n40jleon.html

ScHor, J. (2004). Nacidos para comprar. Los nuevos consumidores infantiles. Barcelona: Paidós.

SiLva, T. (1998). Educación poscrítica, currículum y formación docente. En Alejandra Birgin et ál. (1998).

La formación docente: cultura, escuela y politica: debates y experiencias. (pp. 21-34). Buenos Aires: Troquel Educación SODRé, M. (1998). Reinventando la cultura. Barcelona: Gedisa

Steinberg, R. y Kincheloe, J. (2000). Basta de secretos.

Cultura infantil, saturación de información e infancia postmoderna. En R. Steinberg y J. Kincheloe (Comps.). Cultura infantil y multinacionales. Madrid: Morata.

Thompson, J. (1998). Los Media y la Modernidad. Barcelona: Paidós.

WaLKerdine, V. (1998). La cultura popular y la erotización de las niñas. En J. Curran, D. Morley y V. Walkerdine. (Comps.). Estudios culturales y comunicación. Análisis, producción y consumo cultural de las politicas de identidad y el postmodernismo. Barcelona: Paidós. 